Review Article

\title{
Alternative to Oil and Gas: Review of Economic Benefits and Potential of Wind Power in Pakistan
}

\author{
Xinting Hu, ${ }^{1}$ Muhammad Imran $\mathbb{D}^{2,3}$ Mengyun Wu, ${ }^{2}$ Hee Cheol Moon $\mathbb{D}^{4}$ \\ and Xiaochen Liu ${ }^{1,5}$ \\ ${ }^{1}$ School of Management, Jiangsu University, Zhenjiang 212013, Jiangsu, China \\ ${ }^{2}$ School of Finance \& Economics, Jiangsu University, Zhenjiang 212013, Jiangsu, China \\ ${ }^{3}$ Department of Management Sciences, FATA University, Dara Adamkhel, KPK, Pakistan \\ ${ }^{4}$ Department of International Trade, Chungnam National University, Daejeon 34134, Republic of Korea \\ ${ }^{5}$ School of International Trade \& Economy, Changzhou Vocational Institute of Textile and Garments, Changzhou, China \\ Correspondence should be addressed to Muhammad Imran; imran@ujs.edu.cn and Hee Cheol Moon; hcmoon@cnu.ac.kr
}

Received 26 August 2020; Revised 31 October 2020; Accepted 4 November 2020; Published 29 November 2020

Academic Editor: Licheng Wang

Copyright ( $\odot 2020$ Xinting Hu et al. This is an open access article distributed under the Creative Commons Attribution License, which permits unrestricted use, distribution, and reproduction in any medium, provided the original work is properly cited.

\begin{abstract}
Pakistan is one of those countries that are heavily dependent on hydrocarbon fuel for energy production. This results in severe $\mathrm{CO}_{2}$ emissions that lead to climate change. Although renewable energy resources such as wind are available in abundance, they have not been fully utilized and so energy crises in Pakistan increase every year. This study focuses on using wind energy as an alternative to thermal power sources as the main source of power generation in Pakistan. This research also helps in designing a project management tool to prioritize sources of power generation, including both renewables and nonrenewables, while also considering projects' technical, environmental, social and economic criteria. An Analytical Hierarchy Process has been used to analyze the four main criteria and 12 subcriteria. The analysis revealed that wind energy is the best source among all options for power generation source, followed by solar. Oil, gas, and coal, the other three alternatives, were well below in a comparative analysis. Gas achieves overall better performance if only economic criteria are considered, but due to shortfalls in availability and diminishing reserves, this source is also not feasible. Relying on wind power as the only energy source will not be technically possible, but it can become a leading energy source inside Pakistan. This will reduce the burden on thermal energy sources and make the country more energy-secure, rather than relying heavily on imported oil and gas, as it currently does. Wind power generation capacity in Pakistan is increasing, so that the cumulative capacity is around $2118 \mathrm{MW}$ installed and commissioned by the end of 2018 .
\end{abstract}

\section{Introduction}

Energy plays an important role in shaping a country's economy. In identifying different sources of energy, environmental impact, fuel source, and social impact are very much under consideration. Huge investments have been made in research and development of renewable energy worldwide, not only to counter environmental degradation but to create energy-secure countries [1].

After the oil embargo by Middle Eastern producers against the West in the midseventies, it was realized that other sources of energy must be identified for energy security. Traditional sources of energy are diminishing and will completely die out by the end of this century. The rapidly increasing prices of oil and gas due to instability in the Middle East pose a great risk to any economy [2-6]. Issues around pollution and environmental degradation, whose main causes are greenhouse gases arising from long-term continuous, excessive use of oil, gas, and coal for power generation, have turned world opinion against the use of fossil fuels. The international community is directing policies and strategies towards energy conversion and finding alternative energy sources [7].

Denmark and Italy have reported a high level of wind energy penetration and generated $30 \%$ of their electricity via 
wind. Germany has reported a $22.9 \%$ renewable electric generation [8] (Renewable Energy Policy Network for the 21 st Century). Germany showed much promise in solar energy decades ago, and it reached a landmark when half the country's daytime demand was met by solar power in 2012 $[4,9,10]$. Renewable energy (RE) is spreading across the globe and is becoming increasingly affordable. Developing countries are more interested in improving their RE share compared to developed countries, resulting in shifts of markets and investment to the developing world [8].

1.1. The Case of Pakistan. Pakistan has long been dependent on the use of fossil fuels for the generation of electricity. But the world has changed its priorities in power generation and it is time for Pakistan to find a more sustainable, environmentally friendly, and affordable source of energy for electricity generation as an alternative to fossil fuels. It has three key concerns: reserve exhaustion, environmental degradation, and energy security $[11,12]$. For two decades, Pakistan has been suffering from a severe energy crisis. Power production mainly depends on fossil fuels and there is low production from wind and solar resources. Hence, there is a need to utilize abundantly available wind energy [12-15].

Pakistan's major energy supplies come from oil, coal, gas, hydro, biomass, and nuclear. This makes it a net importer of energy [11]. Sixty percent of its foreign reserves are used for imports of fossil fuels [16]. The power sector alone consumed $40.4 \%$ of total oil used in the country on one recent measure [17].

1.2. Fossil Fuel Consumption. In consumption, natural gas was highest at $49.5 \%$, followed by oil at $30.8 \%$. Of clean energy sources, hydro was a mere $12.5 \%$, which declined from $13.6 \%$ from $2011 / 12$.

During 2011/12, a total of 95,365 GWH of electricity was generated, of which $64.3 \%$ was thermal, $29.9 \%$ hydro, and $5.8 \%$ nuclear and imported [17]. Thus, the bulk of power generation coming from thermal power can be diverted towards industrial usage and reduce the fuel import bill, as shown in Figure 1 above. The bulk of gas (27.8\%) and oil (40.7\%) was used to generate electricity (Figures 2 and 3).

1.3. Problem Statement. The diminishing of fossil fuels inside Pakistan and the stress on existing resources calls for gradual transition towards RE sources $[11,15,18]$. Pakistan has been fortunate in having vast renewable resources, and exploitation of these resources for energy generation is required $[7,14,19]$. Pakistan's energy crisis is not in fact a huge one if we compare it with ongoing developmental work globally.

For the past two decades, hydro power, which was the leading source of power generation in Pakistan, has become problematic. Efforts in this sector slowed down greatly due to political differences [20]. According to the Integrated Energy Plan (IEP) 2009-2022, Pakistan needs to increase its power generation capacity by up to $50,000 \mathrm{MW}$ by 2022 . To achieve this, a $12 \%$ share has to be from alternative energy.



Figure 1: Natural gas consumption in Pakistan by sector (source: Pakistan energy book).

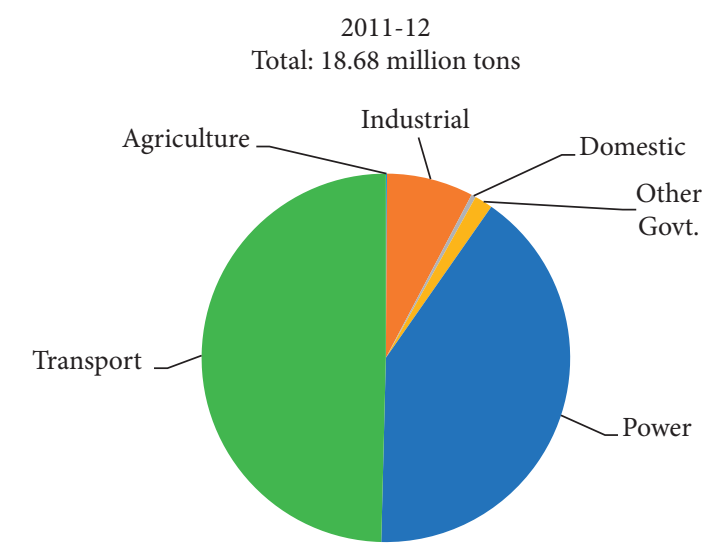

Figure 2: Petroleum consumption in Pakistan by sector (source: Pakistan energy book).

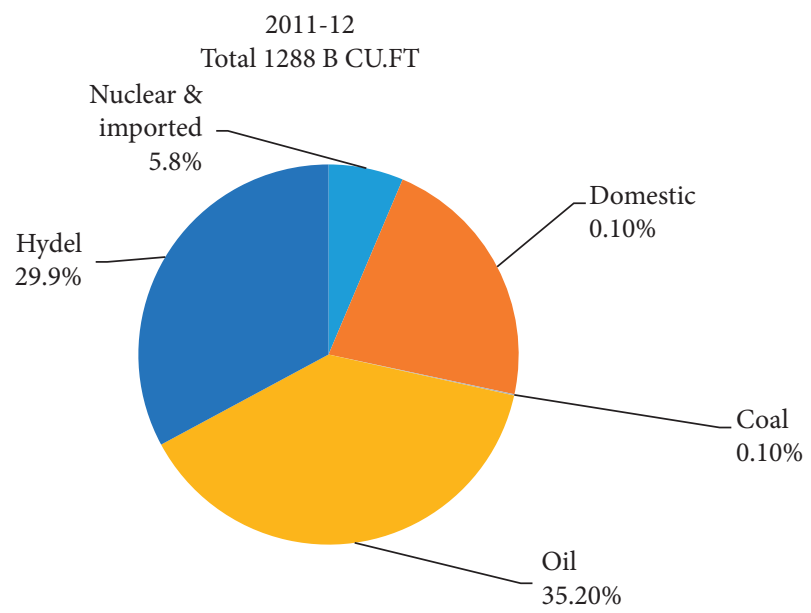

FIgURE 3: Electricity generation 2011-12 by source in Pakistan (source: Pakistan energy book). 
The plan is to install 17,400 MW of alternative clean energy, and 17,392 MW of hydro power installation is also required [21].

Pakistan also relies on fossil fuel, which is also main source of $\mathrm{CO}_{2}$ emissions in the country. In order to reduce dependency on fossil fuels, this study is an effort to investigate the potential of wind power as an alternative to oil and gas.

1.4. Objectives of the Study. Wind power, the cheapest source of energy among alternatives, is considered the best substitute for oil and gas $[4,14,15,20,22-24]$. Pakistan can also find solutions to reduce its reliance on importing oil and utilize natural gas for other purposes instead of using it for generating energy, which can be produced by other alternatives, especially by wind. Exploiting fully a single Gharo Keti Bandar Wind Corridor can resolve current and future energy requirements of the country for many years to come.

The main objective of this study, using the Analytic Hierarchy Process (AHP), is to answer the following questions in empirical terms while considering both qualitative and quantitative data of technical, economic, social, and environmental features of power plants:

What alternative source of power generation is preferable in Pakistan?

How much better is a wind source than non-RE sources?

Can Pakistan completely rely on wind energy as one of the leading sources of power generation?

This study will also help in implementing wind energy projects to meet their goals and in making decisions on power projects with a focus on wind power projects while also considering the environmental and social benefits that arise.

\section{Literature Review}

Fossil fuels have long been a primary source of power generation around the world. Pakistan has been struggling with power shortage for some considerable time. Previous governmental policies to counter power shortages were mainly focused on fossil fuel-based power production. These power plants require oil and gas as their generating fuels. Pakistan does not hold large oil reservoirs, and to meet its demand, it has to rely on imported oil; depletion of gas reservoirs has begun to show its effects.

According to research, the peak fossil fuel use (except for coal) will occur before 2030. The worst-case scenario is that it will occur in 2028: "As peaking is approached, liquid fuel prices and price volatility will increase dramatically and without timely mitigation, the economic, social, and political costs will be unprecedented" [1]. Except for coal, fossil fuel use is expected to diminish by the end of 2042 [5]. To deal with this, the world is trying to build different modes of energy saving technologies and to find different sources of energy [7].
Multi Criteria Decision Making (MCDM) has been used extensively in energy-related problems. It helps governments and organizations plan and make policies in the energy sector by offering an avenue for differing and varied objectives $[23,25,26]$. It has a unique capacity to work on multidimension goals and criteria and can include qualitative as well as quantitative data. A multidimensional criterion permits stakeholders to evaluate and analyze alternatives across numerous dimensions, unlike standard cost benefit analysis, which is one-dimensional. Factors can range from technical, financial, social, and environmental to fuzzy dimensions $[4,27]$. In most decision making, judgments are not crisp and are usually made on intuition and very little expert judgments are involved. It also provides a way to include qualitative data for analysis.

The most commonly used MCDM techniques are Analytic Hierarchy Process, Analytic Network Process, Weighted Sum Method, Weighted Product Method, Preference Ranking Organization Method for Enrichment Evaluation (PROMETHEE II), Elimination and Choice Expressing Reality (ELECTRE), Macbeth, The Technique for Order Preference by Similarity to Ideal Solutions (TOPSIS), and Goal Programming [4, 22, 28, 29]. Pohekar and Ramachandran [26] analysed 90 papers and found out that AHP is the most admired MCDM tool. This is followed by PROMETHEE II and ELECTRE. AHP was developed by Thomas Satty in the 1970s. It has been extensively used in energy planning. This is due to its ability to convert a complex goal structure into a simple hierarchy [26]. The method has been used in energy decision making, resource selection, site selection and impacts on living standards, etc. Ahmad and Tahar [28] and Amer and Daim [20] used it for selection of RE sources and for selection among RE sources inside Pakistan. Stein [4] used AHP to rank both renewable and nonrenewable energy technologies. Kahraman et al. [23] used fuzzy AHP for selection of the most appropriate renewable source. Chatzimouratidis and Pilavachi [29]; Lee et al. [24]; and Akash et al. [30] used AHP with 'Benefits, Opportunities, Costs, and Risks' (BOCR) for selection among wind farms and for comparison between various sorts of renewable and nonrenewable power stations.

2.1. Related Work in Pakistan. A literature review reveals that not much work has been done to find the benefit or loss associated with analyzing all four criteria (technical, economic, social, and environmental) of power plants in Pakistan. Pakistan is one of those countries that are heavily dependent on hydrocarbon fuel for energy production, which results in severe climate change [31,32]. Researchers discussed only the environmental benefits of wind farm projects in Pakistan. Sahira and Qureshi [33] assessed the potential inside the country and the barriers and limitations of RE sources. Mirzaa et al. [34] reported the efforts made for development of wind power in Pakistan and the prospects of improving electricity connectivity through $\mathrm{RE}$ sources in remote areas. Bhutto et al. [7] discussed the prospect of past, present, and future of wind energy in Pakistan along with the hurdles encountered in its development. Amer, M. and 
Daim et al. [20] used AHP to rank only RE sources using European and US data. It was the first effort to rank RE sources in Pakistan but excluded fossil fuel power plants. Prioritizing energy sources, which include both renewable and fossil fuel power plants, and using local data as far as possible are required. This will give a good insight into determining the best energy sources for power production in Pakistan.

Pakistan needs to widen its energy mix to meet its energy demand, given the immense power potential in RE sources. Hydro has long been used as the primary source, whereas solar and wind are prospective energy sources [35]. Pakistan has a vast coastline in the south and places in the northern region which provide excellent wind power potential [32, 34].

There has been a lack of research work in the renewable energy sector in Pakistan to find in empirical terms the benefits of environmental and social aspects of power plants, together with technical and economic aspects, in order to rank different types of energy sources. AHP as a MCDM tool has been used previously but not very effectively because data have been European- and US-based only. For the different criteria and subcriteria, data are unavailable except in a few instances. Using data effectively to rank different technologies is required. AHP helps in prioritizing energy sources and also reveals in empirical terms if wind power is or is not suitable for power generation, compared to other sources. It provides a clear overview of the answers we seek. Wind flows across the planet from higher concentration regions towards areas of lower concentrations. The higher the atmospheric pressure gradient, the higher the wind speed is. A higher speed means greater power can be converted into useful energy. Wind energy has long been used for mechanical means to grind grain or pump water and sail ships across the ocean. With the progress of time and innovation, mechanical power generated through wind energy has been converted into electrical power to light houses $[20,34,36]$.

2.2. Scope of Wind Energy in Pakistan. The Government of Pakistan (GoP) has established two institutes to support the development, guidance, and research work in the RE sector. The Alternative Energy Development Board (AEDB) was established in 2003 as a central body to make possible the growth of RE, to provide support and to develop plans related to RE. The Pakistan Council of Renewable Energy Technologies (PCRET) was established in 2001 to carry out research and development, provide training, and promote RE [20, 37].

Various studies show that wind energy has a great potential in Pakistan and needs to be exploited [33, 34]. A general opinion is that wind energy is the best available option amongst renewable sources in Pakistan [7, 19, 20, 38].

The Government of Pakistan's Integrated Policy 2009-2022 declares the Gharo Keti Bandar wind corridor in Sindh as a permanent wind corridor, thereby removing any prospect of financial interests annulling the land lease by Government of Sindh [21]. The Gharo Keti Bandaar Wind corridor alone has a potential of 60,000 MW [37].
Currently, two wind power projects, a $50 \mathrm{MW}$ Fauji Fertilizer Company Energy Limited (FFCEL) and a $56 \mathrm{MW}$ Zorlu Enerji, have been completed and are contributing electricity to the national grid.

In Figure 4, the shaded regions clearly show large areas suitable for wind energy Exploration. A total of $132 \mathrm{GW}$ wind power can be installed in these windy areas. Almost 9\% of Pakistan's total area has Class 3 or above windy area $[37,39]$. Current sites allocated for Wind Power Projects in Pakistan are in Jhimber, Keti Bnadar, and Gharro, all in Sindh. Table 1 provides a full list of projects.

\subsection{Wind Tariff Determined by NEPRA (National Electric} Power and Regulatory Authority). The Renewable Energy policy announced by Government of Pakistan in 2006 gives tremendous incentives to investors to purchase all their energy from the wind farm at their doorstep. A new and distinctive concept of wind risk has been incorporated to overcome the fears of investors about the reliability and accuracy of wind data $[21,34]$. This concept has been added to ensure wind farm developers are unaffected by circumstances which are outside their control, such as wind speed and density, whereas they are responsible for factors like availability of wind farms, efficiency of wind turbines, etc. [20]. The other provisions are grid access at the door step, economic inducements like tax rebate and asset depreciation, etc. $18 \%$ return on even-handedness, ROE in dollar terms, and repatriation of capital for overseas investors [34].

NEPRA determined the upfront tariff of wind power plant as follows:

Total tariff $=\mathrm{O}$ and $\mathrm{M}+$ insurance + return on equity + Principal repayment of debt + Interest, where $\mathrm{O}$ and $\mathrm{M}=1.6040 \mathrm{Rs} / \mathrm{kwh}$

Insurance $=0.7833 \mathrm{Rs} / \mathrm{kwh}$

Return on equity $=4.6902 \mathrm{Rs} / \mathrm{kwh}$.

The net annual capacity factor for plants was determined at $31 \%$ of the total capacity; excess energy produced shown as below.

The tariff is only applicable to the first $500 \mathrm{MW}$ power after 2013, and the company opting for this tariff must achieve financial closure by the end of 2014 (see Table 2).

The concept of wind risk which was part of Renewable Energy Policy 2006 has been taken away from the upfront tariff. But the successful achievements of Zorlu Enerji and FFCEL wind farm projects make the wind risk concept quite unnecessary.

2.3.1. Upfront Tariff for Solar Photo Voltaic (Solar PV Cells Are Usually Made up of Silicon Cells that Convert Solar Energy to Electricity). The upfront tariff of solar determined by NEPRA reveals that the per MW cost of solar PV is US\$1.9007 Million. This cost of solar energy is much compared to the overnight cost of Solar PV in Annual Energy Outlook, 2011 published by EIA. The cost stands at US\$4.697 Million [4]. 


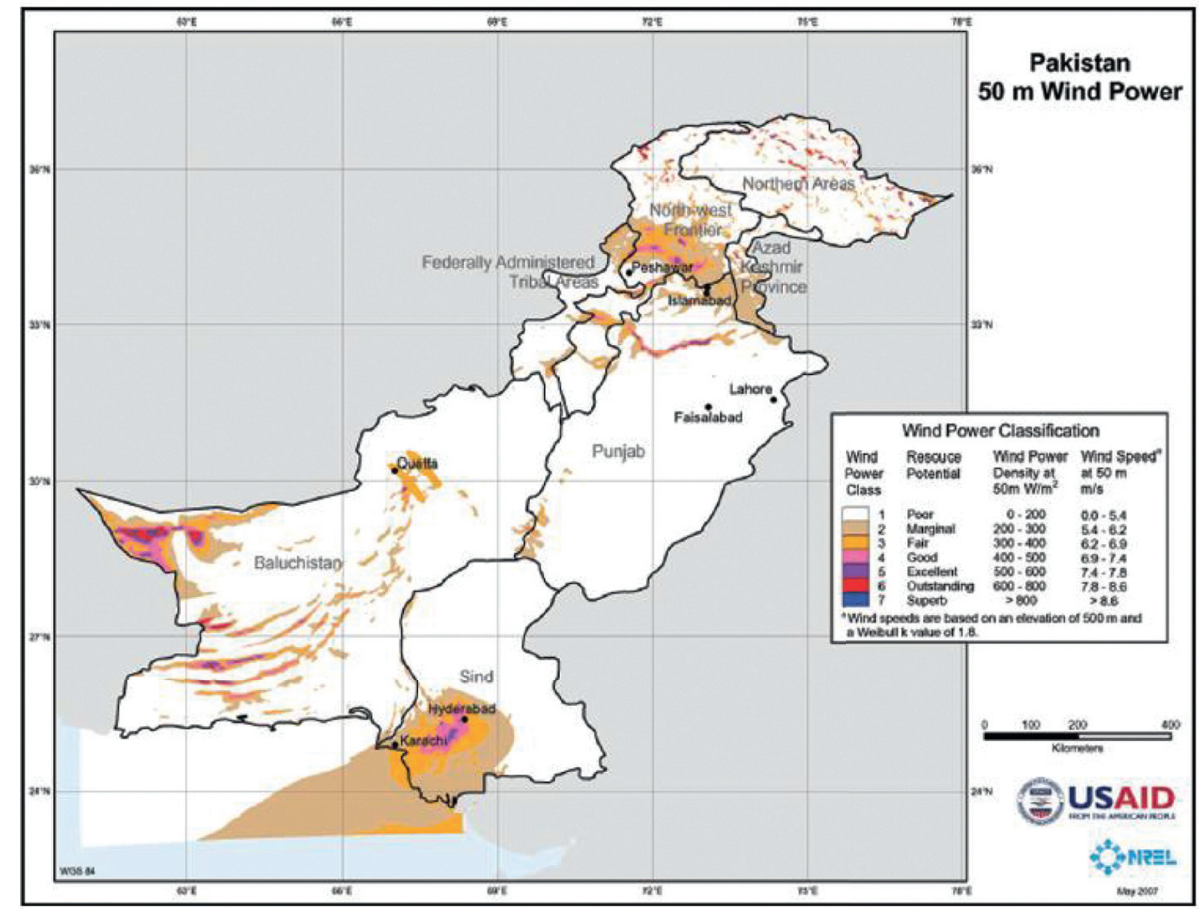

FIgURE 4: Wind power classification map at $50 \mathrm{~m}$ height (source: National renewable energy laboratory (NREL)).

TABLE 1: Land allocation with generation capacity for wind power projects in Pakistan (source: alternative energy development board).

\begin{tabular}{|c|c|c|c|}
\hline S. No. & Company & Project capacity (MW) & Location of land \\
\hline 1 & Tenaga Generasi Ltd & 50 & Kuttikun \\
\hline 2 & Foundation Wind Energy-II Pvt Ltd. (Green Power Pvt Ltd) & 50 & Kuttikun \\
\hline 3 & Hydro China Dawood Power Ltd. & 50 & Bhambore \\
\hline 4 & Master Wind Energy Ltd. & 50 & Jhimper \\
\hline 5 & Zephyr Power Ltd. & 50 & Bhambore \\
\hline 6 & Foundation Wind Energy-I Ltd. (Beacon Energy Ltd) & 50 & Kuttikun \\
\hline 7 & Sachal Energy Development Pvt Ltd. & 50 & Jhimper \\
\hline 8 & Fauji Fertilizer Company Energy Ltd. & 50 & Jhimper \\
\hline 9 & Yunus Energy (Pvt) Ltd. & 50 & Jhimper \\
\hline 10 & Metro Power co.(Pvt) Ltd. & 50 & Jhimper \\
\hline 11 & Gul Ahmed Energy Ltd. & 50 & Jhimper \\
\hline 12 & Zorlu Enerji Pakistan Ltd. & 56.4 & Jhimper \\
\hline 13 & Wind eagle-1 Ltd. & 50 & Jhimper \\
\hline 14 & Wind eagle- 2 Ltd. & 50 & Jhimper \\
\hline 15 & Sapphire Wind Power Company (Pvt) Ltd. & 50 & Jhimper \\
\hline 16 & Three Gorges First Wind Farm Pakistan Pvt. ltd (CWE) & 50 & Jhimper \\
\hline
\end{tabular}

TABLE 2: Capacity factor considered for determination of wind power projects upfront levelized tariff.

\begin{tabular}{lc}
\hline Net annual capacity factor & $\%$ of prevailing tariff \\
\hline Above $31 \%$ to $32 \%$ & 75 \\
Above $32 \%$ to $33 \%$ & 50 \\
Above $33 \%$ to $34 \%$ & 25 \\
Above $34 \%$ to $35 \%$ & 20 \\
Above $35 \%$ & 10 \\
\hline
\end{tabular}

The upfront tariff was calculated for southern and northern regions due to variance in the solar irradiation:

Total Tarrif $=\mathrm{O} \& \mathrm{M}+$ Insurance

$$
+ \text { Return on Equity + Debt Servicing, }
$$

where for the Southern Region, O\&M=1.7391 Rs/kwh, Insurance $=1.1594 \mathrm{Rs} / \mathrm{kwh}$, Return on Equity $=5.8583 \mathrm{Rs} / \mathrm{kwh}$, and Debt Servicing $=12.3570 \mathrm{Rs} / \mathrm{kwh}$ for first ten years.

Hence, the final upfront tariff for the first 10 years of service is up to $21.1138 \mathrm{Rs} / \mathrm{kwh}$ and for the remaining 15 years is $8.7568 \mathrm{Rs} / \mathrm{kwh}$. The levelized cost in US dollars is 16.3063 cents for 25 years.

For the Northern Region, O\&M = 1.8137 Rs/kwh, Insurance $=1.2091 \mathrm{Rs} / \mathrm{kwh}$, Return on Equity $=6.1097 \mathrm{Rs} / \mathrm{kwh}$, and Debt Servicing $=12.8872 \mathrm{Rs} / \mathrm{kwh}$ for first 10 years.

The net final upfront tariff for first 10 years becomes $20.9712 \mathrm{Rs} / \mathrm{kwh}$ and for the remaining 15 years is 8.6976 Rs/kwh. The levelized cost in US dollars for all 25 years becomes $17.0060 /$ kwh cents. 
If the net annual plant capacity factor increases from the cited capacity factors of $16.78 \%$ and $17.50 \%$ for northern and southern regions, respectively, the tariff will be calculated according to Table 3.

2.4. Structural Hierarchy. Structuring the hierarchy between criteria and alternatives is the first step towards achieving the objective in AHP. The hierarchy contains four criteria and 12 subcriteria, as shown in Figure 5.

\section{Technical Criteria}

3.1. Efficiency. Efficiency refers to how much practical energy we can obtain from a resource. High efficiency of an energy source means it is economically feasible $[11,40]$. Efficiency of an energy source is the ratio between the corresponding Btu content of a kWh of electricity (which is $3,412 \mathrm{Btu}$ ) by the heat rate, which is expressed in BTU/kwh [41]. The efficiency of renewables cannot be calculated using the same formula, since they do not require heat to produce electricity [4]. Consequently, the EIA does not have values for hydro, solar, and wind. According to Betz's Law (Betz's Law evaluates the maximum power that can be exploited from wind), theoretically wind turbines can only harness $59.3 \%$ of wind power, but practically their efficiency is around 34\% [4].

3.2. Capacity Factor. Capacity Factor determines how much electricity a power plant will actually produce under real conditions. Most renewables lag behind conventional energy sources when it comes to capacity factors due to seasonal non-availability of energy sources. Thermal power plants have a capacity factor above $80 \%$ and nuclear and geothermal factors at above $90 \%$. The capacity factor for solar is the lowest [41]. The capacity factor determined by NEPRA for upfront tariff determination for wind and solar is $31 \%$ and $17.5 \%$ (Table 4 ).

\subsection{Environment Criteria}

3.3.1. Land Requirement. Electricity generation requires use of land to extract fuel and for installation of power plants; the required land usage can vary from site to site and the power source. This is one of the most important factors in determining the economic value of a power plant [23, 42]. A plant can affect the quality of life, especially when constructed near cities. It can cause rupture in day-to-day activities and the land could have been used for other purposes. In the case of a wind farm, depending upon topography and source availability, a mere $1-10 \%$ of the entire area of a wind farm is used by the wind turbine, sub-station, living areas, and connection roads, and the remaining land is available to be used for farming, grazing, etc., unlike land use by other energy sources [43]. A summary is given in Table 5.

3.3.2. External Costs. External costs have been taken from ExternE Project (ExternE is the well-known acronym for "External Costs of Energy" and a synonym for a series of
TABLE 3: Capacity factor considered for determination of solar PV levelized upfront tariff (source: national electric power regulatory authority).

\begin{tabular}{lc}
\hline Net annual plant capacity factors & $\%$ of the prevalent tariff \\
\hline Above $16.78 \% / 17.50 \%$ to $17.78 \% / 18.50 \%$ & 75 \\
Above $17.78 \% / 18.50 \%$ to $18.78 \% / 19.50 \%$ & 50 \\
Above $18.78 \% / 19.50 \%$ to $18.78 \% / 20.50 \%$ & 25 \\
Above $19.78 \% / 20.50 \%$ to $18.78 \% / 21.50 \%$ & 20 \\
Above $20.78 \% / 21.50 \%$ & 10 \\
\hline
\end{tabular}

projects starting from the early 1990s till 2005; it is an approach for calculating environmental external costs [44]). It ranks all the chief energy technologies in terms of their external costs. These are the hidden costs associated with each technology which affect human health, potentially cause injury, and lead to harm flora and fauna. The data show that wind with an external cost of 0.19 cent/kwh is the lowest cost, whereas coal and oil are among the highest $[4,44]$.

3.3.3. Loss of Life Expectancy. The other decisive factor is Loss of Life Expectancy (LLE). This shows the level of loss of human life ensuing in every phase of the entire period of the power plant (Table 6).

\section{Methodology}

When it comes to evaluating multiple options with conflicting criteria, the multicriteria decision making method is used. This has been used many times for energy problems over the years. It works on several dimensions, allowing the decision to be made across diverse options, including individual opinions.

4.1. Analytical Hierarchy Process. AHP has been used extensively for decision making solutions, ranging from site selection to prioritizing energy sources in corporate and government sectors $[24,45]$. It remains the most widely used and highly regarded approach for decision makers and group decision makers. AHP works by decomposing a multifaceted problem into simple questions and then, further down, into alternative courses of action whose solutions when combined can lead us to answer the original complex problem $[4,46]$. It works by using fuzzy logic rather than permanent and precise ideas. The decisions that we generally make are not absolute but are made up of rational thinking defined only in fuzzy terms. In an effective AHP model, a problem is broken down into a hierarchy, followed by prioritizing the criteria and finally synthesizing the results $[24,47]$. A problem which is the objective of the decision making is at the top of the hierarchy and is decomposed into general criteria, then further broken down into secondary criteria, also called subcriteria, and then into tertiary criteria or sub-subcriteria. The information is then synthesized to decide the relative importance of each alternative. AHP allows both qualitative as well as quantitative data to be analysed. 




Figure 5: Hierarchy structure (source: author's work).

TABLe 4: Technical criteria data.

\begin{tabular}{lcccc}
\hline Type of power plant & Efficiency $^{\mathrm{a}}$ & Availability of fuel (global) & Availability of fuel (local) $^{\mathrm{c}}$ & Capacity factor $^{\mathrm{c}}$ \\
\hline Wind & 35 & 500 & 500 & $31^{\mathrm{d}}$ \\
Solar & 15 & 500 & 500 & 200 \\
Coal & 45 & $107^{\mathrm{b}}$ & $14.5^{\mathrm{d}}$ & $85^{\mathrm{e}}$ \\
Oil & 44 & $31^{\mathrm{b}}$ & 17 & $87^{\mathrm{f}}$ \\
Gas & 39 & $33^{\mathrm{b}}$ & $87^{\mathrm{e}}$ \\
\hline
\end{tabular}

Source: ${ }^{a}$ Euro Electric; ${ }^{\mathrm{b}}[5]$; ${ }^{\mathrm{c}}$ Assumed from data available in Pakistan Energy Year Book, 2012; ${ }^{\mathrm{d}}$ Capacity Factor determined for NEPRA upfront tariff; ${ }^{\mathrm{e}}$ Annual Energy Outlook, 2013; ${ }^{\mathrm{f}}[4]$.

TABLE 5: Land required by technologies for power generation (source: $[20,22]$ ).

\begin{tabular}{lc}
\hline Technology & Land requirement $\left(\mathrm{km}^{2} / 1000 \mathrm{MW}\right)$ \\
\hline Solar PV & 35 \\
Wind & 100 \\
Hydro & 750 \\
Biomass & 5000 \\
Coal & 2.5 \\
Oil & 2.5 \\
Gas & 2.5 \\
Nuclear & 2.5 \\
\hline
\end{tabular}

Structuring the problem is the first phase of the process. This involves recognizing alternatives and defining criteria into a hierarchy. What criterion contributes to which alternative is recognized. After structuring the problem, the criteria are prioritized as the comparative preference of alternatives with criteria.
To determine the criteria weight, pair-wise comparison of one criterion over another is defined. The pair-wise comparison is set in terms of how much $\mathrm{A}$ is more or less significant than $\mathrm{B}$. It can be done using a rough estimate or may be by using a historical data, etc. The historical data can clearly give us comparison data, e.g., if, on an equal measure of fuel, the mileage of a car A is $15 \mathrm{~km}$ and that of car B is $30 \mathrm{~km}$, then car B is clearly twice as efficient as car A. In the cases of no historical data, a rough estimate can be made by experts in that particular field or those who are in decisionlevel positions.

As given below in Table 7, Satty proposed a 9-point comparison scale, where 1 is equally preferred and 9 is extremely preferred $[4,45]$. If alternative $\mathrm{A}$ is less important than alternative $B$, than we enter a reciprocal value like $1 / 5,1 / 7$, etc. When evaluated, the data are further entered into a square matrix "depending upon the number of comparisons" representing all possible comparisons. 
TABLE 6: External cost and Loss of life of different sources of technologies.

\begin{tabular}{lccc}
\hline Technology & External cost $\left(\right.$ EU cent/kwh) ${ }^{\mathrm{a}}$ & ${\text { External cost }(\mathrm{US} \text { cent/kwh })^{\mathrm{b}}}^{\text {LLE }^{\mathrm{b}}(\mathrm{days})^{\mathrm{c}}}$ \\
\hline Solar & 0.60 & 0.834 & $0.1^{\mathrm{d}}$ \\
Wind & 0.19 & 0.2641 & $0.1^{\mathrm{d}}$ \\
Hydro & 0.54 & 0.7506 & 2.3 \\
Biomass & 2.01 & 2.7939 & 3.5 \\
Coal & 5.71 & 7.9369 & 8.4 \\
Oil & 5.70 & 7.923 & 4.5 \\
Gas & 1.85 & 2.5715 & 0.8 \\
Nuclear & 0.39 & 0.5421 & 0.8 \\
\hline
\end{tabular}

Source: ${ }^{\mathrm{a}}$ ExternE; ${ }^{\mathrm{b}}$ Euros converted into US dollars (1 Euro = US \$1.39, as of March 2014); ${ }^{\mathrm{c}}[4]$; ${ }^{\mathrm{d}}$ Negligible (i.e., $<1.0$ ), hence an estimate of 0.1 was used.

TABLE 7: Scale of relative importance according to [45].

\begin{tabular}{lc}
\hline Intensity of importance & Definition \\
\hline 1 & Equal importance \\
2 & Weak \\
3 & Moderate importance \\
4 & Moderate plus \\
5 & Strong importance \\
6 & Strong plus \\
7 & Very strong or demonstrated \\
8 & importance \\
9 & Very, very strong \\
\hline
\end{tabular}

4.2. Evaluation Criteria. A number of objectives supplied the limit of the design of the research. Sources of energy which are being used at a high level, including both RE and non-RE sources, were considered. Therefore, wind, solar, coal, oil, and gas were selected to serve the purpose of alternatives which can also reduce $\mathrm{CO}_{2}$ emissions. In order to evaluate each source of energy alternative on the basis of criteria and subcriteria, four of the most important criteria, Financial, Technical, Environmental and Social, were included. These include all the necessary characteristics for determining the overall significance of a power plant. The criteria and subcriteria have been taken into account in the research. They have been used to analyze coal, oil, and gas, with wind and solar energy as an alternative source of power generation. Twelve subcriteria were identified.

The study was based upon renewable technology and nonrenewable technology. 'Renewable' includes wind and solar; nonrenewable incorporates coal, oil, and gas.

4.3. Data Collection. The data have been collected from international and national organizations. The wind energy-related data have been collected from NEPRA and AEDB sources. The data have also been collected from Fauji Fertilizer Company Energy Limited, a subsidiary company of Fauji Fertilizer Company Ltd. This is the first wind power project in the Pakistan. The data have been collected directly from the site office of the project and also from the official source (Website of FFCEL (http:// www.ffcel.com.pk) and AEDB (http://www.aedb.org)) as shown in Table 8 .
4.4. Expert Choice. Expert Choice is software based upon AHP to help make decisions by adopting a structural approach and prioritizing. Expert Choice has been widely used in the Government sector, industry, and academia to bring together skill, perception, and detailed information. It helps in structuring decisions into smaller levels, assesses the significance of competing dimensions, and further breaks these down into sublevels and defines alternative choices. The process involves not only historic data but also logic and intuition. Expert Choice also allows for an effortless approach to conducting sensitivity analysis by just changing the weights of criteria in order to measure the effect of diverse information for analysis in cases of different outcomes.

4.5. Expert Opinion. To answer the question "Can Pakistan completely rely on wind energy as one of the leading sources of power generation?" experts from the wind sector were chosen to give their opinion. Six experts from FFCEL, Nordex Pakistan Private Limited, and AEDB were asked this question. The question was asked of the Assistant Director Wind (AEDB), the Senior Executive Engineer (FFCEL), the Senior Engineer (FFCEL), the Service Field Operation Manager (Nordex), and two Services Engineers (Nordex).

\section{Empirical Results}

The data have been analysed using the software Expert Choice; which works on the principle of AHP used for MCDM. The model incorporates of four tiers, encompassing criteria, subcriteria, alternatives, and goals. The software accepts both qualitative and quantitative data. The criteria and sub criteria were defined and their relative importance to each other was compared. All the criteria (Economic, Technical, Environmental, and Social) have been considered as of equal importance; the sub criteria were Capacity Factor, Efficiency, Fuel Availability (Local), Fuel Availability (Global), Project Initial Cost, Tariff, Fuel Cost, Land Requirement, LLE, External Cost, Social Acceptance, and Job Creation, all given equal weighting, as shown in Figure 6. The inconsistency ratio for criteria weighting was 0.00 , which showed that all the judgments were perfectly consistent.

The data were entered directly into the data grid, as shown in Figure 6. The subcriteria data were entered by proportion of the total weight of the criteria. The data which were adverse were entered by taking the reciprocal of the 
TABLE 8: Sources of data for AHP.

\begin{tabular}{|c|c|c|}
\hline Criteria & Subcriteria & Source \\
\hline \multirow{7}{*}{ Technical } & \multirow{3}{*}{ Capacity factor } & EIA, Annual Energy Outlook 2013 \\
\hline & & Oil [4] \\
\hline & & Coal, Wind, Solar-NEPRA \\
\hline & \multirow{3}{*}{$\begin{array}{c}\text { Efficiency } \\
\text { Availability of Fuel } \\
\text { (Local) }\end{array}$} & Euro Electric http://www.euroelectric.org \\
\hline & & Assumed from data available in PEYB, 2012 \\
\hline & & \\
\hline & $\begin{array}{l}\text { Availability of Fuel } \\
\text { (Global) }\end{array}$ & [5] \\
\hline \multirow{6}{*}{ Economic } & \multirow{2}{*}{ Project Initial cost } & Oil and Gas-Annual Energy Outlook 2011 \\
\hline & & Wind, Solar coal-NEPRA http://www.nepra.org.pk \\
\hline & & Oil and Gas-An overview of electricity sector in Pakistan 2011, Islamabad Chamber of \\
\hline & Tariff & Commerce and Industries \\
\hline & & Wind, Solar Coal [48] http://www.nepra.org.pk \\
\hline & Fuel cost & {$[4]$} \\
\hline \multirow{3}{*}{ Environmental } & External cost & http://www.ExternE.info \\
\hline & Land requirement & {$[22]$} \\
\hline & LLE & {$[4]$} \\
\hline \multirow{2}{*}{ Social } & Job creation & {$[20,22,29]$} \\
\hline & Social acceptance & European wind energy association http://www.ewea.orh \\
\hline
\end{tabular}

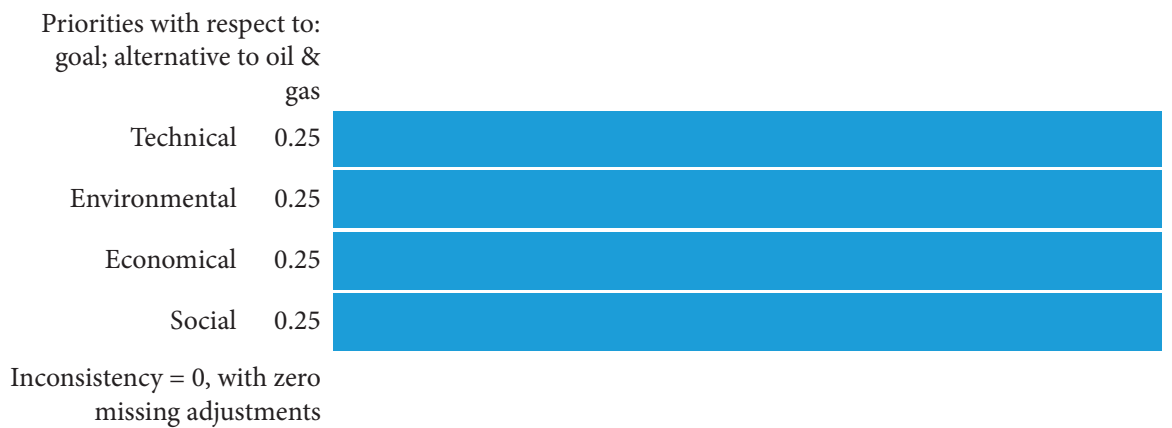

FIgURe 6: Priority graph.

actual value and then taking the percent of every alternative against the total. The overall synthesis of the data with respect to goal, alternative to Oil and Gas, is shown in Figure 7, which shows wind as 0.302 of the total proportion, followed by solar as 0.259 and then by gas, coal, and oil with 0.174 , 0.135 , and 0.130 , respectively.

The results (Figure 7) showed that wind power is the best available resource inside the country, followed by solar. There is a substantial gap between the two renewable and fossil fuel sources.

Wind and solar show that they are excellent sources on all the criteria. The results illustrate that wind and solar offer, by and large, the best benefits across various aspects. They perform well above fossil fuels technically, environmentally and socially. Economically their initial cost is much higher than fossil fuelbased power plants, but in the long run, they outperform them in this criterion as well. Gas also shows equal significance in the economic criteria, but lags behind in the other three criteria against renewable, as shown in Figure 8.

Gas is the most preferred energy source by a short margin, if only the economic criterion is considered, as shown in Figures 9 and 10. The overall result clearly encourages investors to invest in both these green energy sectors, especially wind. The result also provides policy makers with the confidence they require in granting exemptions and benefits to the renewable industry.

Another way to examine the result would be to single out sources which are poorly performing. The sources oil and gas have become an integral part of the power sector in Pakistan: even though they have been proved unsuccessful, they are still being strongly encouraged for their immediate shortterm gains.

\section{Sensitivity Analysis}

In multicriteria decision making, the sensitivity analysis pertaining to the different values and interests is of the utmost importance, since the solutions are judged as acceptable or unacceptable by considering different parameters. The sensitivity analysis was performed to find out how the system would behave if one criterion was given preference over another. However, the results showed very little deviation due to overall strong position taken by both solar and wind in the analysis.

The overall effect can be shown by changing one or more parameters of the criteria in the analysis. Figure 10 shows 


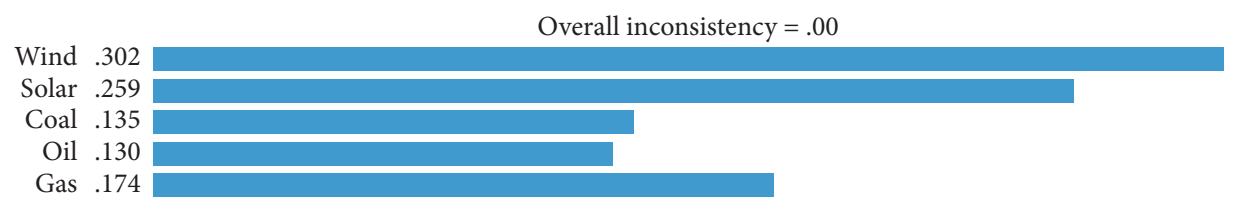

FIGURE 7: Synthesis with respect to goal: alternative to oil and gas.

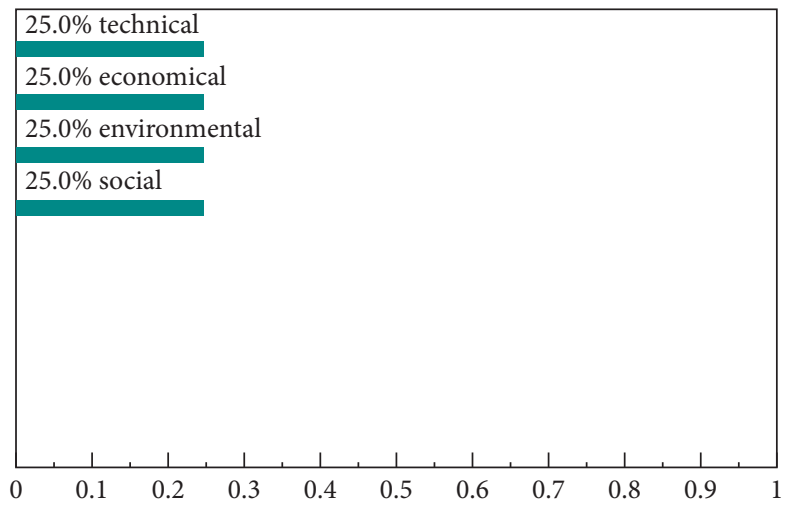

(a)



(b)

FiguRE 8: Ranking of technologies assuming equal weights of all criteria.

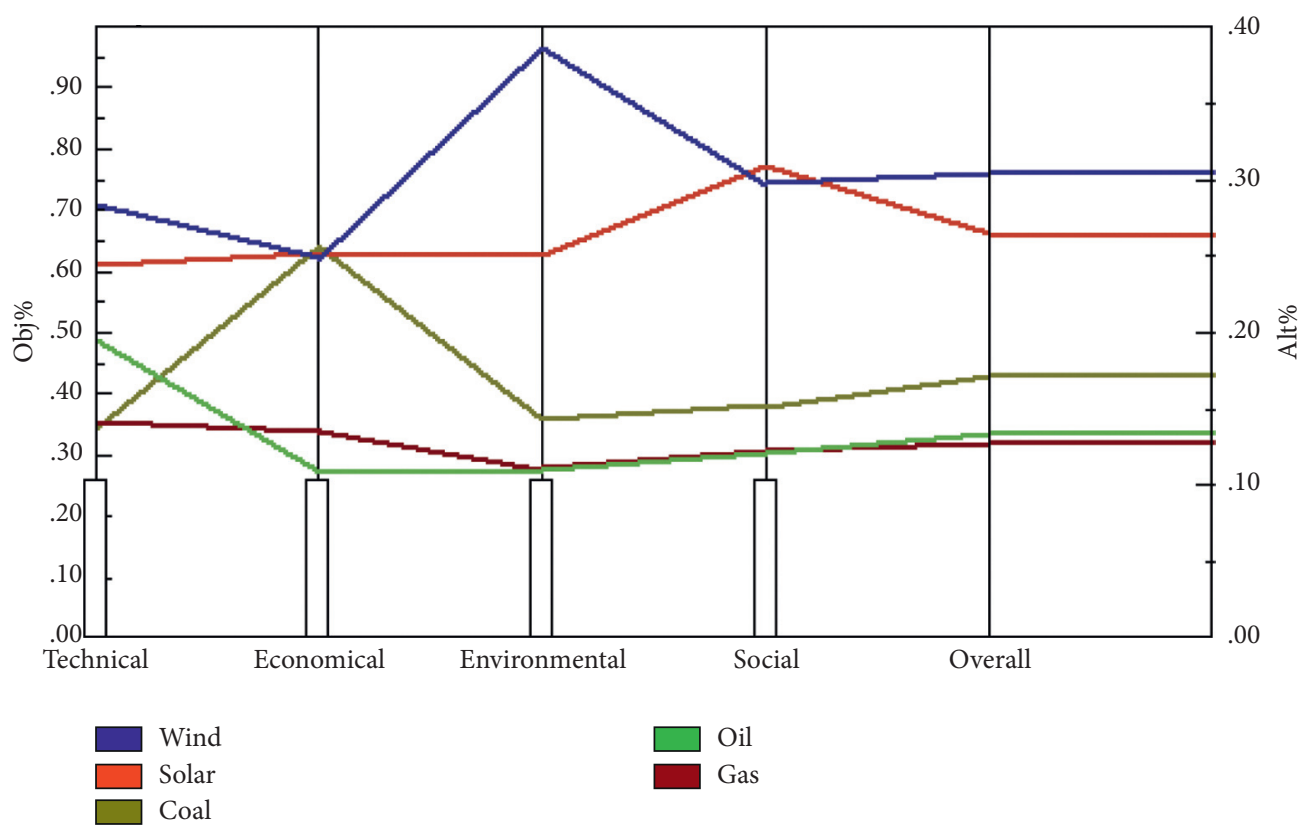

FIGURE 9: Performance sensitivity for each alternative against every criterion with equal weights.

almost similar results as those in Figure 11, even after the economic and technical criteria weights were increased to $45 \%$ each, and the environmental and social criteria were reduced to $5 \%$ each or $1 / 9$ of the above value. Here, the stakeholder main emphasis is on the financial aspect, along with technical characteristics, i.e., efficiency, capacity factor, and availability of fuel for the power plants.

Wind and solar fell a little from the original result but showed an overall dominant position against nonrenewable resources. Similarly, gas was evenly good only in the economic criteria and was lagging in the rest. Both oil and coal showed poor results.

Pakistan's economy is evolving and has inadequate monetary assets. For most policy makers economic criteria would be the most significant. This means that a project's initial cost and tariff are given considerable importance. A similar result was obtained when the economic criteria weight was doubled to 0.4 compared to the other three all 


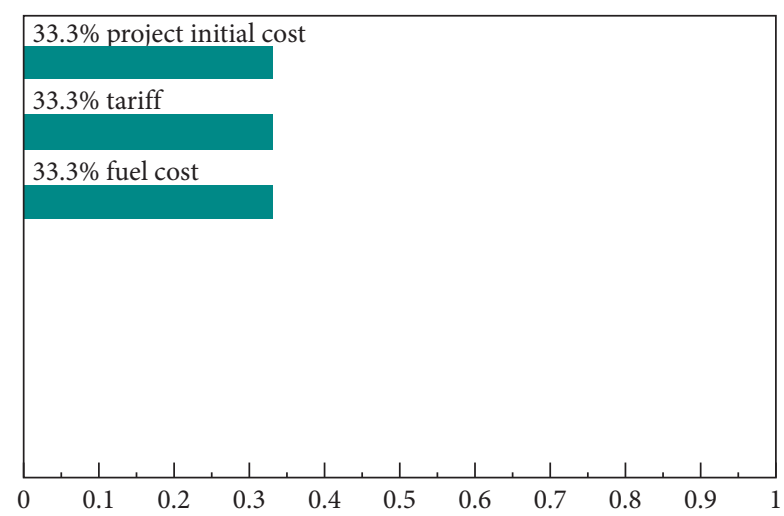

(a)



(b)

Figure 10: Result for economic criteria.

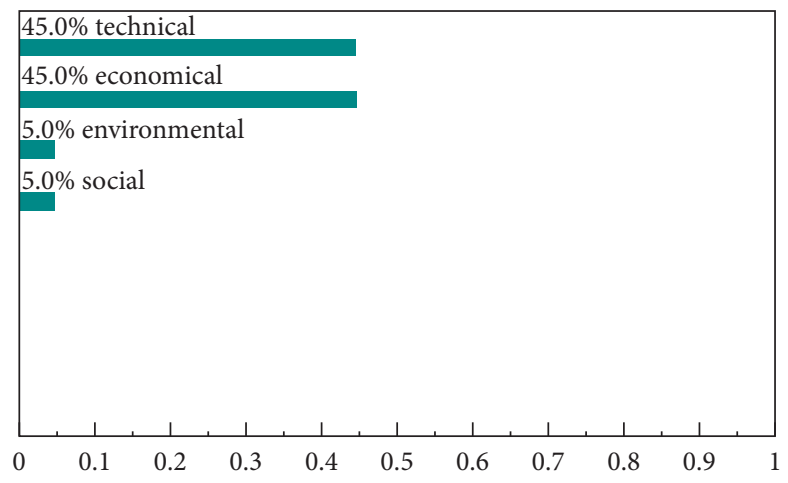

(a)

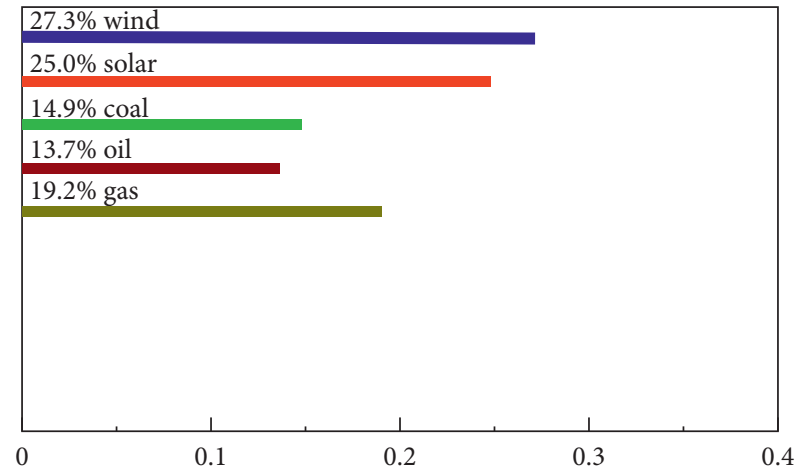

(b)

FIGURE 11: Ranking of all technologies assuming technical and economic criteria as extremely important to environmental and social criteria.

carrying weight of 0.2 . Wind, oil, and gas showed similar results for the economic criteria, whereas wind and solar were better in the remaining three criteria. Wind again performed as the leading energy alternative for power generation in Pakistan, as shown in Figure 12.

By improving the weighing of economic criteria to extremely important, the overall position of gas resources improved, whereas that of wind and solar even after falling remained the best options as an alternative (Figure 13).

By improving the overall weighting of economic criteria to extremely important compared to the rest of the criteria, a steady decline is noted for RE sources, whereas gas improved significantly in its final result but remained behind RE sources (Figure 14).

For most environmentalists, environmental criteria would be the most weighted criteria. The emphasis is on reducing environmental degradation and improving the quality of life of the people, considering the environmental criteria as vital makes wind power a stronger alternative than the rest. Wind improved its proportion, whereas fossil fuel power plants sank down slightly more in the analysis, as shown Figure 15.
A huge difference has been observed in the environmental criteria of wind and solar, which are otherwise considered almost equal, since both are green sources of energy. This is due to the external cost of wind, which is three times lower than that of solar power. The overall result of environmental criteria of both wind and solar is much higher than that of the fossil fuel power plants, with coal and oil scoring just $11.8 \%$ and $11.7 \%$, respectively, as shown in Figure 15.

Generally, renewable sources have been termed the best solution to the growing TWh of energy needs of the world but, due to the high initial setup cost of renewable sources, they have been avoided up till now. In recent years, due to immense R\&D work, the cost has been brought down significantly and they have swiftly become the top priority among investors, as shown in Figure 16.

To answer "Can Pakistan completely rely on wind energy as one of the leading sources of power generation?" experts from different organizations in the wind sector were all of the same view: Pakistan can rely on wind energy as its leading energy source inside the country. But relying on it as a sole source is not technically and economically feasible. 


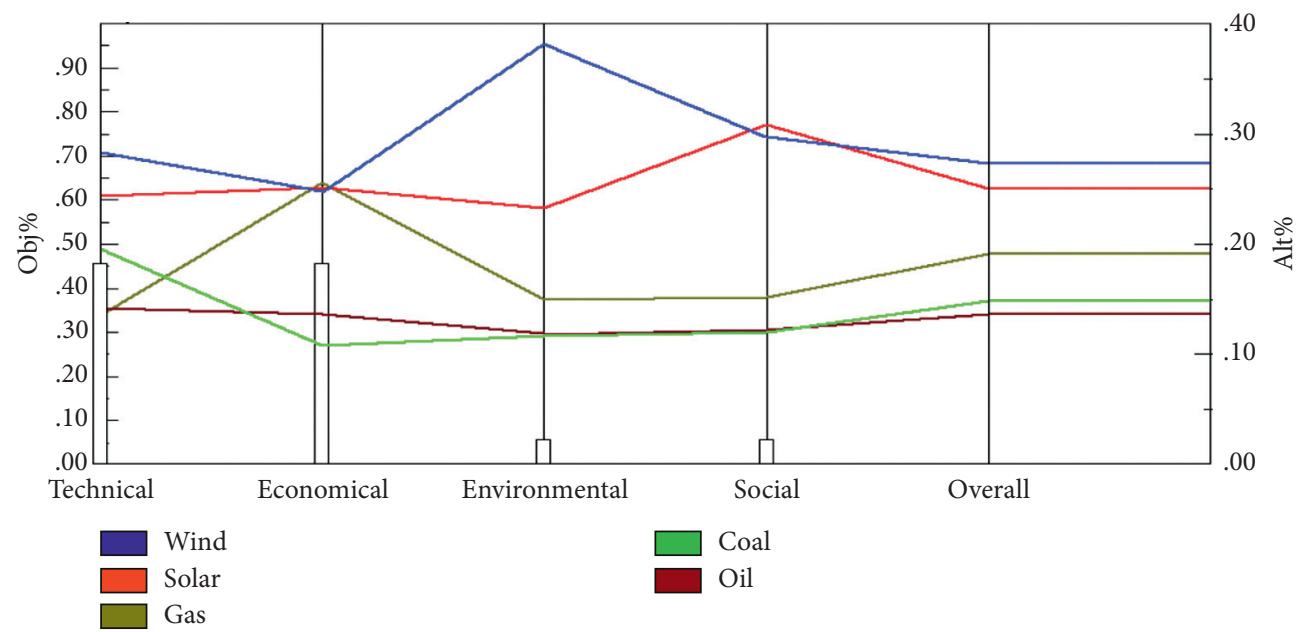

FIgURe 12: Performance sensitivity for each alternative against every criterion with economic and technical criteria being extremely important compared to social and environmental criteria.

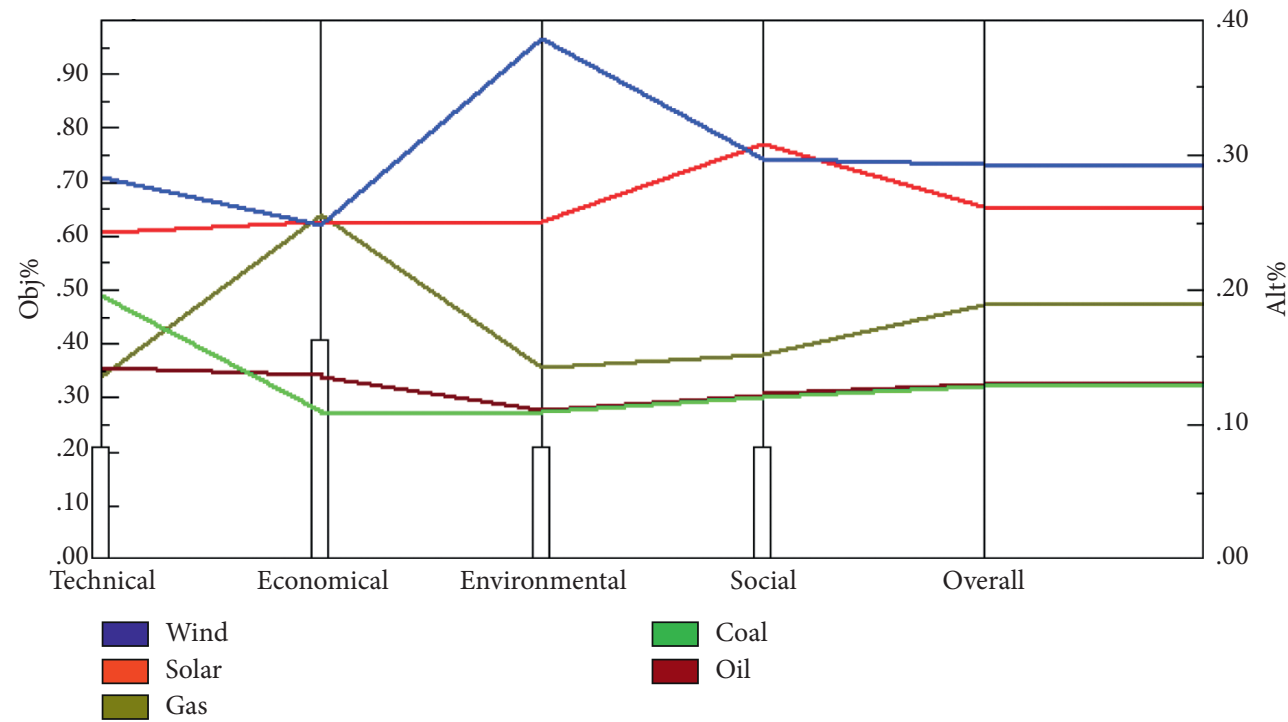

FIgURE 13: Performance sensitivity for each alternative against every criterion with economic criterion weighting twice compared to technical, social, and environmental criteria.

Due to variation in wind speed, power generated cannot be achieved at the desired capacity throughout the year. RE sources as primary sources of energy are best when coupled with nonrenewable energy sources for power generation. Two experts were of the opinion that decision makers can play a pivotal role in promoting it, if they are willing to accept wind as a source for power generation to tackle the energy crisis in the country for current and for future needs.

6.1. Comparison with Previous Research. The review of the literature reveals that studies of multicriteria decision making for selection among different sources were mainly based on the four main criteria of technical, economic, environmental, and social. This clearly shows that the criteria chosen are considered as a foundation for planning and evaluation of power projects. The analysis in this research was based upon these, along with 12 subcriteria carefully chosen after literature study. According to the findings, wind and solar emerge winners when it comes to a comparison with fossil fuel sources. Stein showed similar results in his studies; Amer and Daim [20] listed wind and solar as the best renewable sources for the energy needs of Pakistan.

Chatzimouratidis and Pilavachi $[22,29]$ revealed that RE was a preferable solution compared to conventional fuel power plants. While using AHP and later on PROMETHEE II to analyze the data, they used 13 criteria that were mostly related to environmental and social parameters and excluded economic and technical aspects of power plants. Their results showed minor variation from the results found here. The outcomes showed that wind, solar PV, and geothermal were the best alternatives for power generation. 


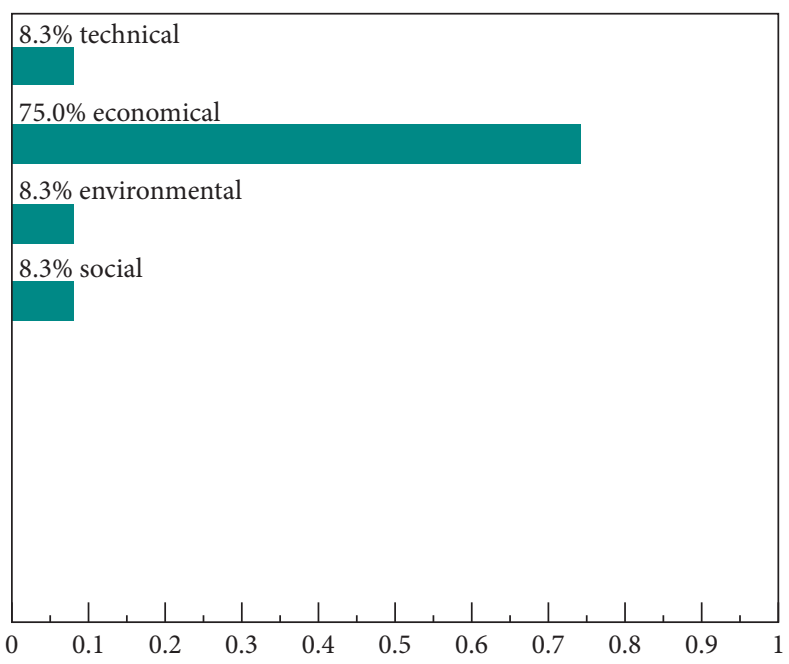

(a)

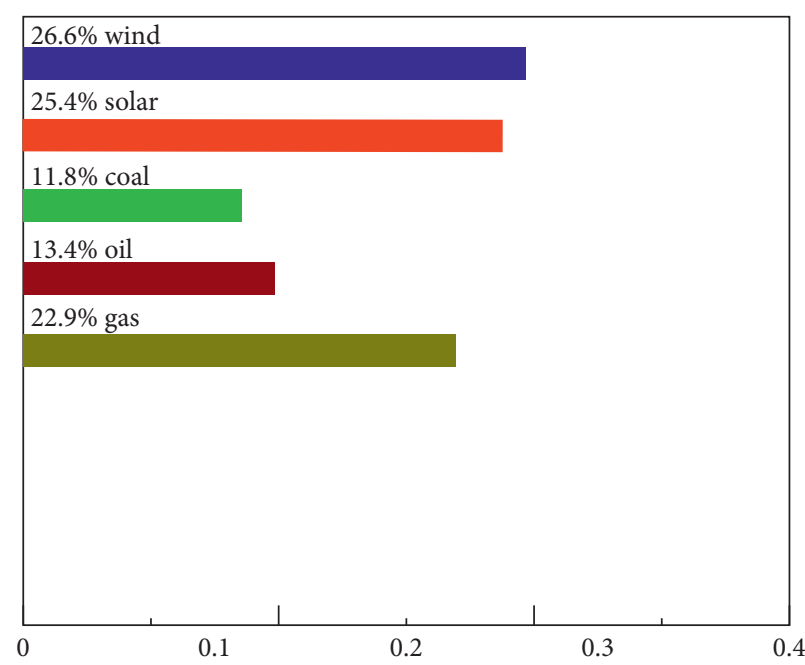

(b)

FIGURE 14: Ranking of all technologies assuming economic criteria extremely important compared to technical, environmental, and social criteria.

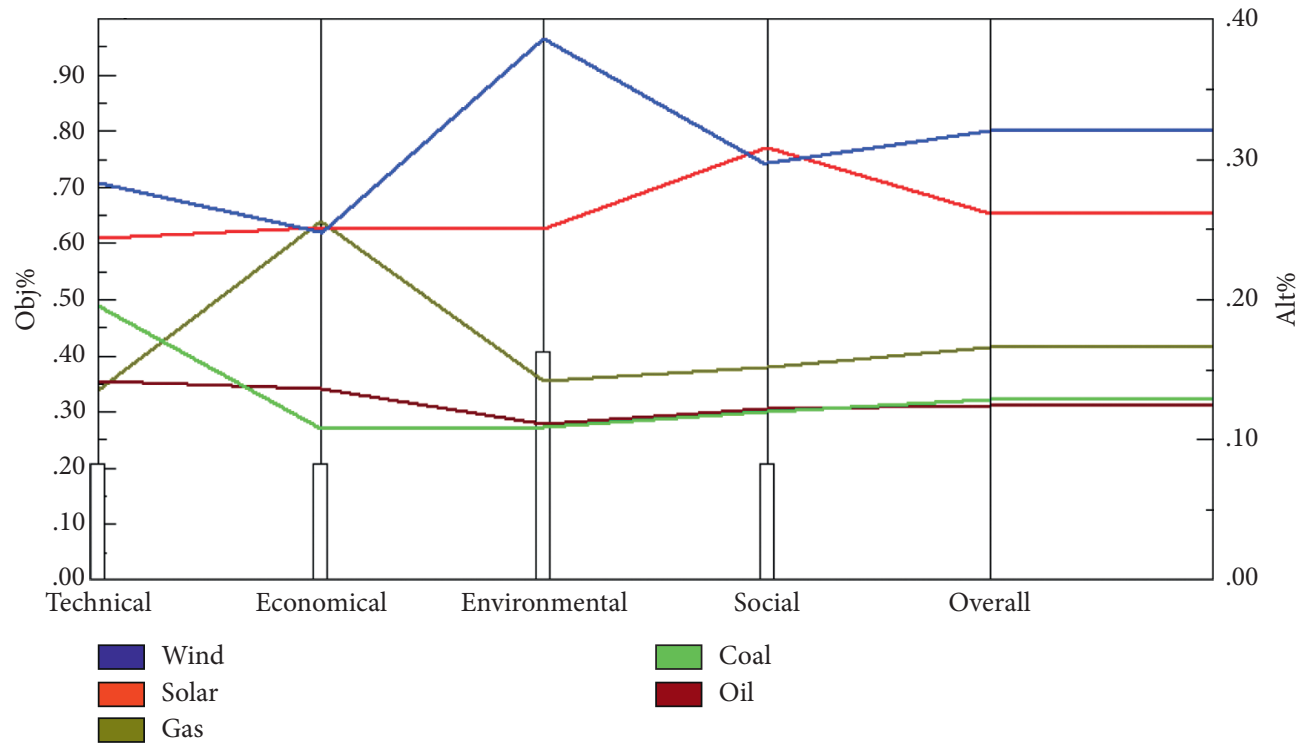

FIGURE 15: Ranking of all technologies assuming environmental criteria twice important compared to technical, economic, and social.

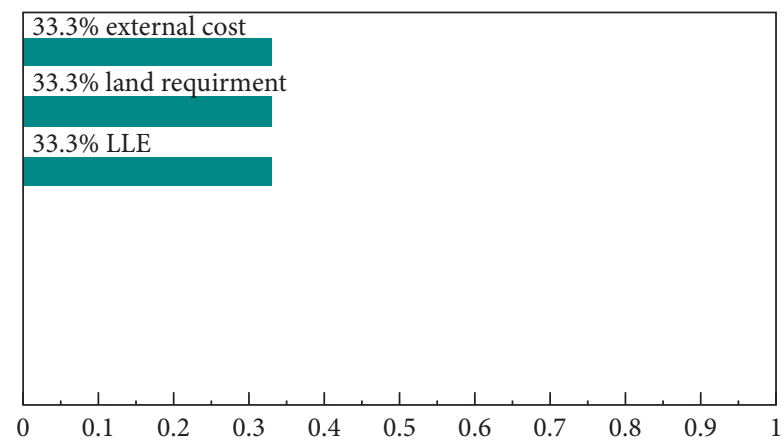

(a)

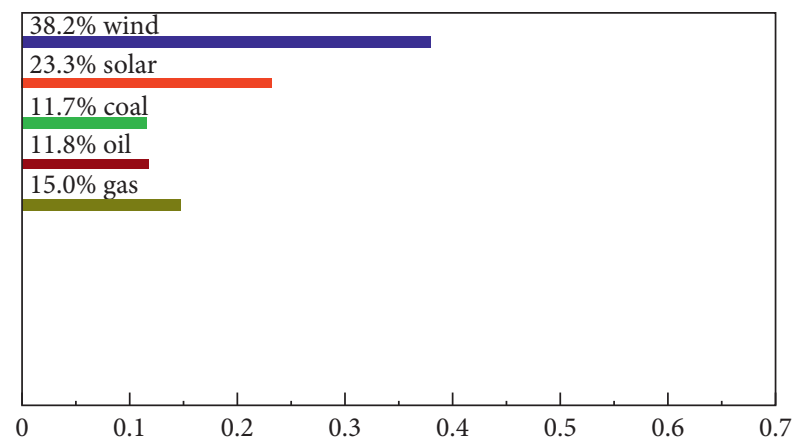

(b)

FIGURE 16: Environmental criteria overall weight when all the criteria were of equal weights. 
They concluded that burning of oil and coal emissions for power generation add greatly to health disorders and mortality and therefore should be avoided.

Amer and Daim's study was based upon the comparison among renewable sources; the results showed that wind was the best alternative, followed closely by solar. They used AHP to analyze their data, which were mainly taken from US and EU data available on the Internet. Their results were similar, with wind topping the renewable list for alternative energy selection [20]. Stein's study was based upon nine alternatives, including renewables and nonrenewables. The power technologies were ranked by assuming equal weights. Wind took the top slot, followed closely by solar and hydro. Biomass was at the very bottom of the list, with coal, oil and gas; nuclear scored similar to fossil fuels [4].

\section{Discussion and Conclusion}

Pakistan's reliance on the use of fossil fuels for generation of electricity has worsened its position. Too much dependence on imports of foreign supplies has made it less energy-secure. The world changed its priorities regarding power generation long ago from fossil fuels towards much more reliable and environmental friendly RE sources. It is high time Pakistan found a consistent and well-designed policy to achieve a more sustainable, environmentally friendly, and affordable source for electricity generation as an alternative to fossil fuels. This will make the country less dependent on fossil fuels and protect it from energy insecurity.

This research gives us an insight into determining the best possible solution to our current energy crisis by considering future requirements. A multiperspective examination for technology appraisal has been used for a variety of available alternatives inside the country. Five alternatives were considered: wind, solar, coal, oil, and gas. The four most essential criteria (Technical, Economical, Environmental, and Social) for energy generation decision making were considered. Twelve subcriteria were measured to determine the four main criteria; all the criteria were equally preferred in their weights. This led us towards our final goal of finding the best solution for power generation in Pakistan.

For the first time, actual data from Pakistan's wind and solar sectors were used in order to prioritize among the energy alternatives inside the country. The data available on the NEPRA website were used for consideration of tariff and initial cost of power projects and subcriteria of economic criteria for wind, solar, and coal-based power plants. The capacity factor, a subcriterion of technical criteria for wind and solar, was taken from the upfront tariff determined by NEPRA.

The analysis revealed that RE easily outperformed fossil fuel power plants by a lengthy margin. Wind power as an alternative and RE source surpassed every other alternative. Gas showed good economic standing but the question remains: for how long? Gas is unable to tackle the energy crisis due to lower production capacity, and with meager resources, this can get worse. Unless more and abundant gas reservoirs can be explored, it will remain a bad choice for power generation. Thermal sources cannot be totally ignored but too much dependence on them should be avoided. The overall result calls for decision makers to focus on the RE sector, chiefly wind energy, as its driving force for future power generation. The policies devised to improve the share of RE mix must not only be maintained but expanded. Subsidies given to fossil fuels, if they remain necessary, must be truncated phase-wise to discourage the inclination towards them. Expenditure for fuel imports will be reduced and can be diverted towards operational cost and towards new investments prospects to drive more jobs. Wind power can improve the overall energy security of a country.

Pakistan as a country is highly insecure in terms of energy due to too-much dependence on fossil fuel power plants. Every now and then, there is fuel shortage supply to thermal power plants due to payment issues or problems faced due to poorer gas supply to the power plants. This in turn brings power outages, making the domestic and industrial customers suffer and affecting the whole business sphere. This has had a depressing impact on the industrial sector, and exports have suffered greatly due to high tariff rates along with high power outages. Focusing on wind and other renewables to improve the overall energy mix in the country will improve energy security. As the contribution of RE improves in the energy mix, the price of electricity will become more insensitive to the fluctuation in oil prices in the international market; thus, a steadier electricity price would be easily maintained. This gives investors and industrialists an incentive in the form of a cheaper and steadier tariff without affecting their productivity, which is usually very disturbed by power outages. Altogether, this will give confidence and investment security to customers to work inside the country.

The resources in Pakistan will not last forever, and so investing in RE and making the industry stronger will help in the long run to secure future employment. In addition, the health of the people can benefit from these technologies, which can in turn improve the savings and economic status of the people. Producing energy from renewable sources, especially wind, will prevent emissions of nonradioactive gases produced in Pakistan. This will evidence of the eagerness of the Government to improve its share of RE in the overall energy mix in accordance with the Kyoto Protocol.

The FFCEL wind farm project, which achieved a Commercial Operation Date (COD) on 16 May 2014, has successfully injected 129GWh of green energy into the National Grid in its first year of operation. The average availability factor for the first four months, i.e., from midMay till mid-August 2014, was nearly $88 \%$, which improved significantly and has been at 99\% since October 2014 through to March 2015. If this trend of high availability was accomplished from the first day of COD, the power generated would have been significantly higher. The maximum availability factor can be easily managed with a quick response service team. The benchmark power for a complete year for the FFCEL wind farm was calculated to be $143 \mathrm{GWh}$, which is achievable. It is assumed that the capacity factor can be above $31 \%$ or more if $98-99 \%$ of the wind farm availability factor is achieved. Hence, it can be concluded that the capacity factor for the wind farm in our sample area of 
Jhimper is much higher than the one assumed by NEPRA for tariff determination.

Pakistan has vast land areas with wind potential, spread across all four provinces. The current focus in wind power is limited to the Gharro, keti Bandar, and Jhimper wind corridor, all near the coastal belt of Sindh Province, for utilizing all the wind power potential at a single place. But this focus should also be shifted to other parts of the country, especially towards the wind corridor near Mardan region and Islamabad. This will attract many investors who would find these places more desirable to invest in as being nearer to the federal capital. On the other hand, wind power supported with hydro electricity could be a good solution to tackle the power crisis. Even though hydro power has its own limitations, it still remains the best option as the most economical source of power generation. Wind at the southern region and hydro in the northern region of the country can be technically sound. By providing two nodes for the electricity supply system at the two far ends of the country, the distribution losses along the path can be reduced immensely.

Wind energy was followed by solar energy. Solar energy has been termed equally good, but, due to its higher cost, it has not enjoyed much success around the world. According to the Annual Energy Outlook 2011, the project initial cost for Solar PV has been around 4697 \$KW. This is the highest of all after nuclear power. The project's initial cost considered by NEPRA for tariff determination is around $1901 \$ / \mathrm{KW}$. This huge difference in cost remains a mystery in itself which needs to be cleared up. If this initial cost of solar power is true for Pakistan in all respects, then solar power projects can be much more economical than previously believed.

7.1. Limitations. Renewable energy offers many advantages in terms of copious free fuel and ease of use but there are also limitations to their availability all day long. Even though wind energy is one of the leading sources of power generation around the globe, wind power cannot be used as the only source of power generation and is only successful when supported by other sources of power generation, preferably nuclear energy in Pakistan's case. Wind as an energy source is never available around the clock. Wind turbine output varies with the temperature of the surroundings, and the speed, density, and intensity of wind. Wind is stronger and often available during summer, but in winter wind stops blowing hard and is not available as frequently as in summer. This makes the capacity factor of a wind farm much lower compared to other sources of power generation, creating many barriers to continuous supply of power.

\section{Data Availability}

The data used in this paper can be retrieved from Pakistan Energy Book.

\section{Conflicts of Interest}

The authors declare that they have no conflicts of interest.

\section{Acknowledgments}

The authors take this opportunity to thank the editorial board members Kai Wang, Wang Licheng, and Andrew Mendoza. This research was supported by the National Social Science Fund (19BGL127), the National Natural Science Fund (71572071), the China Postdoctoral Science Foundation Funded Project (2015M571708), and the $\mathrm{Hu}-$ manities and Social Sciences Fund of the Ministry of Education (18YJA630074).

\section{References}

[1] L. M. W. Leggett and D. A. Ball, "The implication for climate change and peak fossil fuel of the continuation of the current trend in wind and solar energy production," Energy Policy, vol. 41, pp. 610-617, 2012.

[2] G. A. Olah, "Beyond oil and gas: the methanol economy," Angewandte Chemie International Edition, vol. 44, no. 18, pp. 2636-2639, 2005.

[3] B. K. Savacool and M. A. Brown, "Competing dimensions of energy security: an international perspective," Annual Review of Environment and Resources, vol. 35, pp. 77-108, 2010.

[4] E. W. Stein, "A comprehensive multi-criteria model to rank electric energy production technologies," Renewable and Sustainable Energy Reviews, vol. 22, pp. 640-654, 2013.

[5] S. Shafiee and E. Topal, "When will fossil fuel reserves be diminished?” Energy Policy, vol. 37, no. 1, pp. 181-189, 2009.

[6] X. Long, Y. Chen, J. Du, K. Oh, and I. Han, "Environmental innovation and its impact on economic and environmental performance: evidence from Korean-owned firms in China," Energy Policy, vol. 107, pp. 131-137, 2017.

[7] A. W. Bhutto, A. A. Bazmi, and G. R. Zahedi, "Greener energy: issues and challenges for Pakistan-wind power prospective," Renewable and Sustainable Energy Reviews, vol. 20, pp. 519538, 2012.

[8] REN21, "Renewable energy policy network for 21st century," 2013.

[9] Wharton, "University of pennsylvania," 2012.

[10] H. Sun, A. K. Kporsu, T. Farhad, and E. Bless Kofi, "Estimating environmental efficiency and convergence: 1980 to 2016," Energy, vol. 11, 2020.

[11] T. Muneer and M. Asif, "Prospects for secure and sustainable electricity supply for Pakistan," Renewable and Sustainable Energy Reviews, vol. 11, no. 4, pp. 654-671, 2007.

[12] H. Sun, B. K. Edziah, and A. K. Kporsu, "Institutional quality, green innovation and energy efficiency," Energy Policy, vol. 135, p. 111002, 2019.

[13] Z. Usman, R. Tanzeel, K. A. Abbas, and R. Muhammad, “An overview of implemented renewable energy policy of Pakistan," Renewable and Sustainable Energy Reviews, vol. 82, pp. 654-665, 2018.

[14] M. Shoaib, I. Siddiqui, Y. M. Amir, and S. U. Rehman, "Evaluation of wind power potential in Baburband (Pakistan) using Weibull distribution function," Renewable and Sustainable Energy Reviews, vol. 70, pp. 1343-1351, 2017.

[15] M. Kamran, "Current status and future success of renewable energy in Pakistan," Renewable and Sustainable Energy Reviews, vol. 82, pp. 609-617, 2018.

[16] M. A. Sheikh, "Energy and renewable energy scenario of Pakistan," Renewable and Sustainable Energy Reviews, vol. 14, no. 1, pp. 354-363, 2010. 
[17] HDIP, "Pakistan energy year book," Hydrocarbon Development Institute of Pakistan, Ministry of Petroleum and Natural Resources, Government of Pakistan, vol. 14, 2012.

[18] S. N. Malik and O. R. Sukhera, "Management of natural gas resources and search for alternative renewable energy resources: a case study of Pakistan," Renewable and Sustainable Energy Reviews, vol. 16, no. 2, pp. 1282-1290, 2012.

[19] M. M. Qurashi and T. Hussain, "Renewable energy technologies for developing countries now and to 2023," 2005.

[20] M. Amer and T. U. Daim, "Selection of renewable energy technologies for a developing county: a case of Pakistan," Energy for Sustainable Development, vol. 15, no. 4, pp. 420435, 2011.

[21] IEP, "Integrated Energy Plan 2009-2022," Ministry of Finance, Government of Pakistan, vol. 16, 2009.

[22] A. I. Chatzimouratidis and P. A. Pilavachi, "Decision support systems for power plants impact on the living standard," Energy Conversion and Management, vol. 64, pp. 182-198, 2012.

[23] C. Kahraman, İ. Kaya, and S. Cebi, “A comparative analysis for multiattribute selection among renewable energy alternatives using fuzzy axiomatic design and fuzzy analytic hierarchy process," Energy, vol. 34, no. 10, pp. 1603-1616, 2009.

[24] A. H. I. Lee, H. H. Chen, and H.-Y. Kang, "Multi-criteria decision making on strategic selection of wind farms," Renewable Energy, vol. 34, no. 1, pp. 120-126, 2009.

[25] J.-J. Wang, Y.-Y. Jing, C.-F. Zhang, and G.-H. Shi, “A fuzzy multi-criteria decision-making model for trigeneration system," Energy Policy, vol. 36, no. 10, pp. 3823-3832, 2009.

[26] S. D. Zhang and M. Ramachandran, "Application of multicriteria decision making to sustainable energy planning-A review," Renewable and Sustainable Energy Reviews, vol. 8, no. 4, pp. 365-381, 2004.

[27] J.-J. Wang, Y.-Y. Jing, C.-F. Zhang, and J.-H. Zhao, "Review on multi-criteria decision analysis aid in sustainable energy decision-making," Renewable and Sustainable Energy Reviews, vol. 13, no. 9, pp. 2263-2278, 2009.

[28] S. Ahmad and R. M. Tahar, "Selection of renewable energy sources for sustainable development of electricity generation system using analytic hierarchy process: a case of Malaysia," Renewable Energy, vol. 63, pp. 458-466, 2014.

[29] A. I. Chatzimouratidis and P. A. Pilavachi, "Multicriteria evaluation of power plants impact on the living standard using the analytic hierarchy process," Energy Policy, vol. 36, no. 3, pp. 1074-1089, 2008.

[30] B. A. Akash, R. Mamlook, and M. S. Mohsen, "Multi-criteria selection of electric power plants using analytical hierarchy process," Electric Power Systems Research, vol. 52, no. 1, pp. 29-35, 1999.

[31] B. V. Mathiesen, H. Lund, and K. Karlson, "100\% Renewable energy systems, climate mitigation and economic growth," Applied Sciences, vol. 88, pp. 488-501, 2011.

[32] M. Khalid Saeed, A. Salam, A. U. Rehman, and M. Abid Saeed, "Comparison of six different methods of Weibull distribution for wind power assessment: a case study for a site in the Northern region of Pakistan," Sustainable Energy Technologies and Assessments, vol. 36, 2019.

[33] M. H. Sahir and A. H. Qureshi, "Assessment of new and renewable energy resources potential and identification of barriers to their significant utilization in Pakistan," Renewable and Sustainable Energy Reviews, vol. 12, no. 1, pp. 290-298, 2008.
[34] U. Mirza, N. Ahmad, T. Majeed, and K. Harijan, "Wind energy development in Pakistan," Renewable and Sustainable Energy Reviews, vol. 11, no. 9, pp. 2179-2190, 2007.

[35] M. Asif, "Sustainable energy options for Pakistan," Renewable and Sustainable Energy Reviews, vol. 13, no. 4, pp. 903-909, 2009.

[36] W. Tong, Wind Power Generation and Wind Turbine Design, WIT Press, Boston, MA, USA, 2010.

[37] AEDB, "Alternative energy development board," 2014.

[38] F. Dincer, "The analysis on wind energy electricity generation status, potential and policies in the world," Renewable and Sustainable Energy Reviews, vol. 15, no. 9, pp. 5135-5142, 2011.

[39] NREL, "National renewable energy laboratory," 2012.

[40] S. K. Lee, G. Mogi, and J. W. Kim, "Decision support for prioritizing energy technologies against high oil prices: A fuzzy analytic hierarchy process approach," Journal of Loss Prevention in the Process Industries, vol. 22, no. 6, pp. 915-920, 2009.

[41] EIA, "Energy information agency," 2014.

[42] M. Z. Jacobson and M. A. Delucchi, "Providing all global energy with wind, water, and solar power, Part I: technologies, energy resources, quantities and areas of infrastructure, and materials," Energy Policy, vol. 39, no. 3, pp. 1154-1169, 2011.

[43] V. Fthenakis and H. C. Kim, "Land use and electricity generation: a life-cycle analysis," Renewable and Sustainable Energy Reviews, vol. 13, no. 6-7, pp. 1465-1474, 2009.

[44] ExternE, "ExternE-external costs of energy," 2006.

[45] Satty and L. Thomas, The Analytic Hierarchy Process: Planning, Priority Setting, Resource Allocation, McGraw-Hill, New York, NY, USA, 1980.

[46] K. v. Alphen, W. G. V. Sark, and P. Hekkert, "Renewable energy technologies in the Maldives-determining the potential," Renewable and Sustainable Energy Reviews, vol. 11, no. 8, pp. 1650-1674, 2007.

[47] M. Mohsin, J. Zhang, R. Saidur, H. Sun, and S. M. Sait, "Economic assessment and ranking of wind power potential using fuzzy-TOPSIS approach," Environmental Science and Pollution Research, vol. 26, no. 22, pp. 22494-22511, 2019.

[48] NEPRA, "National electric power regulatory authority," 2013. 